\title{
PERANAN GAYA KEPEMIMPINAN DAN LATAR BELAKANG PENDIDIKAN DALAM MENINGKATKAN KINERJA KARYAWAN PT. INFOMEDIA SOLUSI HUMANIKA
}

\author{
${ }^{1}$ Heni Cahya Ramdani, ${ }^{2}$ Femi Handayani, \& ${ }^{3}$ Islamiyah \\ 1, 2, 3FKIP Ekonomi, Universitas Islam Syekh Yusuf Tangerang \\ Email: hcramdani@unis.ac.id
}

\begin{abstract}
The purpose of this study to determine the roles of leadership and educational background in enhancing employee's performance. The sample was 50 employees of PT. Infomedia Solusi Humanika. The method used in this research was descriptive quantitative and the analysis can be concluded that the leadership style has given positive and significant impact on employee's performance but education background has not given positive impact. Both, the leadership style and educational background showed significantly influence to the performance of PT. Infomedia Solusi Humanika'employees.
\end{abstract}

Keywords: leadership style, education, performance. 


\section{A. PENDAHULUAN}

Perkembangan teknologi saat ini membawa dampak pada media komunikasi baru yang diaplikasikan pada layanan customer service. Penggunaan media sosial pada layanan customer service dipandang sebagai cara yang mudah untuk sarana berkomunikasi dengan pelanggan lama maupun baru sebagai sarana berkomunikasi dengan pelanggan. Media sosial dianggap lebih efektif dari pada menggunakan cara-cara lama.

Hampir semua perusahaan yang memenangkan customer service award di Indonesia telah menggunakan media sosial dan saluran digital lainnya untuk mendekatkan diri dengan konsumen melalui layanan customer support yang lebih relevan. Konsumen di zaman ini bisa merasakan apa yang tidak pernah dirasakan konsumen di zaman sebelumnya. Kecepatan respons, personalisasi layanan, dan follow-up adalah kunci utama dari keberhasilan perusahaan. Untuk mencapai keberhasilan tersebut, Sumber Daya Manusia yang dimiliki perusahan memiliki peranan yang sangat penting.

Sumber Daya Manusia (SDM) memegang peranan paling penting dan potensial bagi keberhasilan suatu perusahaan, mengingat SDM merupakan penentu kegiatan perusahaan baik perencanaan, pengorganisasian, serta pengambilan keputusan (Kapahang, Kojo, \& Uhing, 2014, p.504). SDM harus digunakan sebaik-baiknya dan dikembangkan kemampuannya agar hasil kerjanya produktif. Kualitas SDM sebuah organisasi merupakan salah satu faktor utama baik atau buruknya organisasi.

Sumber daya lain yang dimiliki oleh perusahaan seperti modal, metode dan mesin tidak bisa memberikan hasil yang optimal apabila tidak didukung oleh sumber daya manusia yang mempunyai kinerja berkualitas. Tujuan dari sebuah organisasi atau perusahaan itu sendiri yaitu memajukan usahanya yang lebih bergantung pada kinerja karyawan.

Kinerja karyawan yang tinggi merupakan salah satu syarat dalam pencapaian tujuan perusahaan. Dalam sebuah perusahaan atau organisasi, untuk tercapainya suatu manajemen yang baik ialah bagaimana suatu pelaku manajemen bisa memanage (mengatur) kondisi lingkungan dalam sebuah perusahaan agar terciptanya manajemen yang efektif dan efesien (Guterres \& Supartha, 2016, p.430-431). Tentu saja dalam hal ini sangat diharapkan ketika gaya kepemimpinan bisa berkontribusi dan bekerjasama dengan Team Work. Sehingga para karyawan bisa mengikuti intruksi seorang Leader (pemimpin), sehingga akan meningkatkan kinerja karyawan. 
PERANAN GAYA KEPEMIMPINAN DAN LATAR BELAKANG PENDIDIKAN

DALAM MENINGKATKAN KINERJA KARYAWAN PT. INFOMEDIA SOLUSI HUMANIKA

Heni Cahya Ramdani, Femi Handayani, E Islamiyah

Seorang pemimpin memiliki posisi tertentu dalam hierarki organisasi. Ia harus dapat membuat perencanaan, pengorganisasian, dan pengawasan serta keputusan yang efektif. Seorang pemimpin juga dapat mempengaruhi moral, kepuasan kerja, keamanan, kualitas kehidupan kerja dan terutama tingkat prestasi suatu organisasi (Saputra \& Natassia, 2014, p.135). Kemampuan dan ketrampilan kepemimpinan dalam pengarahan adalah faktor penting efektivitas seorang pemimpin. Di dalam suatu organisasi,faktor kepemimpinan memegang peranan penting agar dapat mempengaruhi bawahan sehingga tujuan yang telah direncanakan dapat tercapai secara efektif dan efisien. Oleh karena itu, dibutuhkan adanya pemimpin di dalam suatu organisasi untuk melakukan pengaturan, pengarahan dan pendayagunaan sumber-sumber daya yang ada.

Kepemimpinan pada setiap organisasi merupakan faktor yang sangat penting dan menentukan keberhasilan suatu organisasi. Suksesnya kepemimpinan ditunjukkan dengan keberhasilan mengelola organisasi untuk mencapai tujuan-tujuannya dan tujuan-tujuan pribadi yang terlibat didalamnya.

Selain pentingnya perananan gaya kepemimpin, pendidikan merupakan faktor yang perlu diperhatikan oleh suatu organisasi atau perusahaan. Pendidikan dipergunakan untuk mempersiapkan pegawai dalam memikul tanggung jawab yang berbeda atau lebih tinggi didalam organisasi (Pentana \& Ardiani, 2016, p.436). Pegawai dengan tingkat pendidikan lebih tinggi akan memiliki kematangan secara emosional dan kemampuan intelektual lebih baik dibanding pegawai yang hanya memiliki pendidikan lebih rendah. Pegawai dengan tingkat pendidikan lebih tinggi akan bertindak lebih terarah karena memiliki kemampuan koseptual lebih baik.

Tingkat pendidikan yang baik, dapat menunjang keberhasilan perusahaan dalam mencapai tujuan perusahaan. Dengan tingginya tingkat pendidikan akan mampu mengoptimalkan kinerja karyawan dan produktivitas kerja karyawan, sehingga akan meningkatkan produktivitas perusahaan (Setiawan, 2015, p.2). Semakin tinggi tingkat pendidikan karyawan, semakin handal pula dalam mencermati kinerjanya, karyawan yang handal dalam pekerjaannya akan menghasilkan output yang lebih baik.

Keberhasilan sebuah perusahaan bisa dilihat dari hasil kinerja karyawan yang dimiliki melalui beberapa parameter yang telah ditentukan. Perusahaan yang akan diteliti kali ini adalah PT. Infomedia Solusi Humanika yang menangani bidang Customer Service Social Media 
Telkomsel atau bisa disebut juga E-Care Telkomsel. Berikut adalah hasil penilaian kinerja karyawan bulan Desember dari bebera parameter, diantaranya: Knowledge of Job $86 \%$ dari target 90\%, Quality of Work $98 \%$ dari target 95\%, Quantity E Timeline of Work 32\% dari target 35\%, Productivity $86 \%$ dari target $100 \%$, Sustainability $7 \%$ dari target $15 \%$, Attendance $\mathcal{E}$ Punctuality $26 \%$ dari target $30 \%$. Realisasi dari parameter penilaian kinerja bulan Desember, masih belum mencapai target yang ditentukan oleh perusahaan, kecuali pada parameter Quality of Work. Dari data di atas, seorang pemimpin dan latar belakang pendidikan sangat berperan penting dalam mencapai keberhasilan sebuah perusahaan, khususnya di PT. Infomedia Solusi Humanika.

Berdasarkan uraian di atas maka permasalahan yang akan diangkat dalam penelitian ini adalah:

1. Apakah Gaya Kepemimpinan berpengaruh signifikan terhadap kinerja karyawan di E-Care Telkomsel PT. Infomedia Solusi Humanika?

2. Apakah Latar Belakang pendidikan berpengaruh signifikan terhadap Kinerja karyawan di E-Care Telkomsel PT. Infomedia Solusi Humanika?

3. Apakah Gaya Kepemimpinan dan Latar Belakang Pendidikan berpengaruh terhadap Kinerja karyawan di E-Care Telkomsel PT. Infomedia Solusi Humanika?

\section{B. TINJAUAN PUSTAKA \\ Kinerja Karyawan}

Kinerja adalah "suatu hasil kerja yang dicapai seseorang dalam melaksanakn tugas-tugas yang dibebankan kepadanya didasarkan atas kecakapan, pengalaman, dan kesungguhan serta waktu" (Hasibuan, 2007, p. 105). Kinerja karyawan adalah apa yang dilakukan oleh seorang karyawan yang mempengaruhi seberapa banyak mereka memberi kontribusi kepada organisasi yaitu dalam arti kualitas, kuantitas output, jangka waktu output, kehadiran di tempat kerja, dan sikap kooperatif (Mathis, 2002, p. 78).

\section{Gaya Kepemimpinan}

Kepemimpinan adalah cara seorang pemimpin mempengaruhi perilaku bawahannya agar mau bekerjasama dan bekerja secara produktif untuk mencapai tujuan organisasi (MUJIATUN, 2011, p.78). Gaya kepemimpinan merupakan suatu cara pemimpin untuk mempengaruhi 
PERANAN GAYA KEPEMIMPINAN DAN LATAR BELAKANG PENDIDIKAN

DALAM MENINGKATKAN KINERJA KARYAWAN PT. INFOMEDIA SOLUSI HUMANIKA

Heni Cahya Ramdani, Femi Handayani, \& Islamiyah

anggotanya yang dinyatakan dalam bentuk pola tingkah laku atau kepribadian (Saputra \& Natassia, 2014, p.135).

\section{Latar Belakang Pendidikan}

Pendidikan adalah untuk mempersiapkan SDM sebelum memasuki pasar kerja. Dengan pengetahuan yang diperolehnya dari pendidikan yang diharapkan sesuai dengan syarat-syarat yang dituntut oleh suatu pekerjaan Zainun dalam (Dini \& Sari, 2013, p.61). Pendidikan sangat diperlukan dalam rangka meningkatkan kualitas sumber daya manusia dalam memajukan perusahaan, karena pendidikan merupakan modal dasar bagi karyawan dalam melakasankan pekerjaan dan bertujuan untuk membantu pencapaian tugas agar mencapai hasil kerja yang baik. Pentingnya pendidikan bukan semata-mata bagi karyawan tetapi juga bagi organisasi dalam rangka peningkatan kemampuan karyawan untuk menghasilkan kinerja yang maksimal (Kapahang, Kojo, \& Uhing, 2014, p.504).

\section{Hasil Penelitian Yang Relevan}

Penelitian ini mengenai Gaya Kepemimpinan dan Latar belakang pendidikan dalam meningkatkan Kinerja Karyawan pada PT. Infomedia Solusi Humanika. Berdasarkan eksplorasi peneliti, di temukan beberapa tulisan yang berkaitan dengan penelitian ini.

1. Andri Saputra \& Rizky Natassia (2014), "Pengaruh Gaya Kepemimpinan Dan Motivasi Kerja Terhadap Kinerja Karyawan Badan Pusat Statistik ( Bps ) Kota Padang" terdapat pengaruh positif dan signifikan antara gaya kepemimpinan terhadap motivasi kerja karyawan pada Badan Pusat Statistik (BPS) Kota Padang.

2. Jennifer Octora Kapahang, Christoffel Kojo, Yantje Uhing (2014), "Pendidikan, Pengalaman Dan Kompetensi Pengaruhnya Terhadap Kinerja Karyawan Pada Pt. Pln (Persero) Wilayah Suluttenggo" Pendidikan berpengaruh positif dan signifikan terhadap Kinerja Karyawan PT. PLN (Persero) wilayah Suluttenggo. Pendidikan, Pengalaman Kerja dan Kompetensi secara simultan berpengaruh terhadap Kinerja Karyawan PT. PLN (Persero) wilayah Suluttenggo. 
3. R. Okky Satria \& Husaeri Priatna (2012), “Pengaruh Gaya Kepemimpinan, Komitmen dan kepuasan kerja terhadap kinerja karyawan" Pengaruh Gaya Kepemimpinan sangat signifikan terhadap Kinerja Karyawan di PD BPR Kabupaten Bandung Kantor Cabang Banjaran. Pengaruh Komitmen sangat signifikan terhadap Kinerja Karyawan di PD BPR Kabupaten Bandung Kantor Cabang Banjaran. Pengaruh Gaya Kepemimpinan, Komitmen dan Kepuasan Kerja sangat signifikan terhadap Kinerja Karyawan di PD BPR Kabupaten Bandung Kantor Cabang Banjaran.

4. Evert Fandi Mandang, Bode Lumanauw, Mac D.B. Walangitan (2017), "Pengaruh tingkat pendidikan dan pelatihan terhdap kinerja karyawan pada PT. Bank Rakyat Indonesia (persero) cabang manado" tingkat Pendidikan dan Pelatihan secara simultan berpengaruh signifikan terhadap Kinerja Karyawan Pada PT Bank BRI Cabang Manado. Tingkat Pendidikan secara parsial tidak berpengaruh signifikan terhadap Kinerja Karyawan Pada PT Bank BRI Cabang Manado. Pelatihan secara parsial berpengaruh signifikan terhadap Kinerja Karyawan Pada PT Bank BRI Cabang Manado.

5. Sopi Pentana\&Winda Ardiani (2016), “Dampak Latar belakang pendidikan, prlatihan dan penempatan pegawai terhadap kinerja pegawai" Berdasarkan hasil uji statistika secara simultan pendidikan, pelatihan dan penempatan berpengaruh positif dan signifikan terhadap Kinerja pegawai. Berdasarkan hasil uji statistika secara parsial pendidikan berpengaruh positif dan signifikan terhadap Kinerja pegawai.

\section{METODE PENELITIAN}

Penelitian ini di lakukan di PT. Infomedia Solusi Humanika. Waktu yang diperlukan dalam proses penelitian adalah kurang lebih selama 6 bulan terhitung mulai dari bulan Maret sampai dengan bulan Agustus 2018.

Penelitian ini mengacu pada pendekatan penelitian kuantitatif. Metode penelitian Kuantitatif dapat di artikan sebagai metode penelitian yang berlandaskan pada filsafat positivisme, di gunakan untuk meneliti pada populasi atau sampel tertentu, teknik pengambilan sampel pada umumnya dilakukan secara random, pengumpulan data menggunakan instrumen penelitian, analisis data bersifat kuantitatif/statistik dengan tujuan untuk menguji hipotesis yang telah di terapkan (Sugiono, 2015, p. 14). 
PERANAN GAYA KEPEMIMPINAN DAN LATAR BELAKANG PENDIDIKAN

DALAM MENINGKATKAN KINERJA KARYAWAN PT. INFOMEDIA SOLUSI HUMANIKA

\section{Teknik Pengumpulan Data}

Heni Cahya Ramdani, Femi Handayani, \& Islamiyah

Penelitian ini dilakukan dalam bentuk penelitian lapangan, sedangkan metode yang digunakan ialah deskriptif analisis. Metode survey deskriptif merupakan metode penelitian yang mengambil sampel dari suatu populasi dan menggunakan kuesioner sebagai alat pengambilan data. Dalam penelitian ini, data dan informasi dikumpulkan dari responden dengan menggunakan kuesioner. Setelah data diperoleh kemudian hasilnya akan dipaparkan secara deskriptif dan pada akhir penelitian akan dianalisis untuk menguji hipotesis yang diajukan pada awal penelitian ini (Effendi, 2003, p. 3).

\section{Teknik Analisis Data} Uji Normalitas

Uji Normalitas data adalah uji yang dimaksudkan bahwa data sampel berasal dari populasi yang berdistribusi normal. Suatu data di katakan berdistribusi normal apabila jumlah data di atas dan di bawah mean sama. Uji normalitas dilakukan untuk menguji data variabel bebas $(\mathrm{X})$ dan variabel terikat $(\mathrm{Y})$. Data yang mempunyai distribusi normal brarti data tersebut dapat di katakan mewakili populasi. Untuk mengetahui sebaran tiap variabel normal atau tidak, dapat di lakukan dengan melihat nilai signifikan pada tabel Kolmogorov-Smirnov. Data di katakan memiliki distribusi yang normal adalah data yang memiliki nilai signifikasi lebih dari 0,05 , sedangkan jika nilai signifikansinya lebih kecil dari 0,05 maka data tersebut dinyatakan tidak berdistribusi normal. Akan tetapi dalam penelitian ini, uji normalitas data dilakukan menggunakan bantuan program komputer SPSS Statistics 22.

\section{Uji Linieritas}

Uji linieritas digunakan untuk mengetahui linieritas data, yaitu apakah dua variabel mempunyai hubungan yang liniear atau tidak. Uji ini digunakan sebagai prasyarat dalam analisis korelasi pearson atau regresi linier. Kriteria pengujian linieritas adalah apabila $\mathrm{F}_{\text {hitung }}$ lebih kecil dari $\mathrm{F}_{\text {tabel }}$ ( $F_{\text {hitung }}<\mathrm{F}_{\text {tabel }}$ ) pada taraf signifikansi 5\%, maka hubungan variabel bebas $(X)$ dengan variabel terikat $(\mathrm{Y})$ dinyatakan linier. Pengujian SPSS 22 dengan menggunakan Test For Linearity.

\section{Uji Multikolinieritas}

Multikolinieritas adalah antarvariabel independen yang terdapat dalam model regresi memiliki hubungan linier yang sempurna atau mendekati sempurna (Koefisien korelasinya tinggi atau bahkan 1).Untuk 
mengetahui regresi tersebut terjadi multikolinieritas atau tidak, banyak metode yang digunakan, salah satu metode yang populer digunakan dalam analisis multikolinieritas adalah dengan melihat nilai VIF (Varian Inflation Faktor) dari hasil perhitungan analisis kolinieritas.Jika nilai VIF $>10$, maka dikatakan pasti ada kolinieritas. Dan sebaliknya jika ViF $<10$, maka dikatakan tidak terdapat kolinieritas, dengan demikian multikolinieritas harus dihindari dari model regresi yang akan dibentuk.

\section{Uji Heteroskedastisitas}

Heteroskedastisitas adalah varian residual yang tidak sama pada semua pengamatan di dalam model regresi. Uji heteroskedastisitas berarti tidak terpenuhinya asumsi yang menyatakan bahwa distribusi bersyarat dari tiap populasi $Y$ yang sesuai untuk nilai $X$ tertentu mempunyai varians yang sama, dalam hal ini, masing-masing nilai $\mathrm{Y}$ tersebar disekitar nilai rata-ratanya dengan varians yang sama. Dengan kata lain uji heteroskedastisitas bertujuan untuk menguji apakah dalam model regresi terjadi ketidaksamaan varian dari residual satu pengamatan ke pengamatan yang lain, atau kondisi dimana sebaran atau varian tidak konstan sepanjang observasi.

\section{Analisis Regresi Linear Berganda}

Digunakan untuk mengukur kuat atau tidaknya pengaruh variabel $\mathrm{X}_{1}$ (Gaya Kepemimpinan), $\mathrm{X}_{2}$ (Latar Belakang Pendidikan) dengan variabel Y (Kinerja Karyawan). 
PERANAN GAYA KEPEMIMPINAN DAN LATAR BELAKANG PENDIDIKAN DALAM MENINGKATKAN KINERJA KARYAWAN PT. INFOMEDIA SOLUSI HUMANIKA

\section{HASIL DAN PEMBAHASAN}

$$
\text { Heni Cahya Ramdani, Femi Handayani, E Islamiyah }
$$

\section{Uji Normalitas}

Tabel 1. Tests of Normality

\begin{tabular}{lcccccc}
\hline & \multicolumn{3}{c}{$\begin{array}{c}\text { Kolmogorov- } \\
\text { Smirnova }\end{array}$} & \multicolumn{3}{c}{ Shapiro-Wilk } \\
\cline { 2 - 7 } & Statistic & df & Sig. & Statistic & df & Sig. \\
\hline $\begin{array}{l}\text { Gaya } \\
\text { Kepemimpinan }\end{array}$ & 0,117 & 50 & 0,087 & 0,974 & 50 & 0,338 \\
\hline $\begin{array}{l}\text { Latar Belakang } \\
\text { Pendidikan }\end{array}$ & 0,121 & 50 & 0,066 & 0,960 & 50 & 0,086 \\
$\begin{array}{l}\text { Kinerja } \\
\text { Karyawan }\end{array}$ & 0,114 & 50 & 0,100 & 0,980 & 50 & 0,546 \\
\hline
\end{tabular}

1. Data Gaya Kepemimpinan nilai sig $=0,087>0,05$, maka dapat disimpulkan bahwa data Gaya Kepemimpinan berdistribusi normal.

2. Data Latar Belakang Pendidikan nilai sig $=0,066>0,05$, maka dapat disimpulkan bahwa data Latar Belakang Pendidikan berdistribusi normal.

3. Data kinerja karyawan nilai sig $=0,100<0,05$, maka dapat disimpulkan bahwa data kinerja karyawan berdistribusi normal.

\section{Uji Linieritas}

\section{Tabel 2. Hasil Uji Linieritas}

Gaya Kepemimpinan Terhadap Kinerja Karyawan

\begin{tabular}{|c|c|c|c|c|c|c|c|}
\hline & & & $\begin{array}{l}\text { Sum of } \\
\text { Squares }\end{array}$ & Df & $\begin{array}{l}\text { Mean } \\
\text { Square }\end{array}$ & $\mathrm{F}$ & Sig. \\
\hline \multirow{6}{*}{$\begin{array}{l}\text { Gaya } \\
\text { Kepemimpinan* } \\
\text { Kinerja } \\
\text { Karyawan }\end{array}$} & \multicolumn{2}{|c|}{ Between (Combined) } & 854,646 & 17 & 50,273 & 10,551 & ,000 \\
\hline & \multirow[t]{3}{*}{ Groups } & Linearity & 745,293 & 1 & 745,293 & 156,416 & 000 \\
\hline & & Deviation & & & & & \\
\hline & & $\begin{array}{l}\text { From } \\
\text { Linearity }\end{array}$ & 109,353 & 16 & 6,835 & 1,434 & ,188 \\
\hline & \multicolumn{2}{|c|}{ Within Groups } & 152,474 & 32 & 4,765 & & \\
\hline & \multicolumn{2}{|c|}{ Total } & 1007,120 & 49 & & & \\
\hline
\end{tabular}

Berdasarkan output pada table 2 uji linieritas antara variabel bebas (Gaya Kepemimpinan $\mathrm{X}_{1}$ ) dengan variabel terikat (Kinerja karyawan $\mathrm{Y}$ ) dilihat dari Deviation From Linearity, menurut hasil perhitungan didapatkan 
nilai sig Deviation From Linearity sebesar 0,188 antara Gaya Kepemimpinan dengan kinerja karyawan. Menurut kriterianya jika harga Deviation From Linearity lebih besar dari taraf signifikansi yang diambil (5\%) berarti berhubungan linier tetapi jika harga Deviation From Linearity lebih kecil dari taraf signifikansi yang diambil (5\%) berarti berhubungan tidak linier. Dalam penelitian ini terbukti bahwa Deviation From Linearity antara variabel bebas dengan variabel terikatnya adalah lebih besar terhadap taraf signifikansinya 0,05 $(0,188>0,05)$. Maka dapat disimpulkan bahwa Gaya Kepemimpinan $\left(\mathrm{X}_{1}\right)$ dengan kinerja karyawan $(\mathrm{Y})$ bersifat linier. Artinya hubungan atau korelasi tersebut dapat dinyatakan dengan garis lurus. Apabila mempunyai hubungan atau korelasi yang linier positif maka variabel satu meningkat dan variabel yang lain akan meningkat, tetapi apabila korelasi atau hubungan yang linier negatif variabel satu meningkat maka variabel yang lain akan menurun.

Tabel 3. Hasil Uji Linieritas Latar Belakang Pendidikan Terhadap Kinerja Karyawan

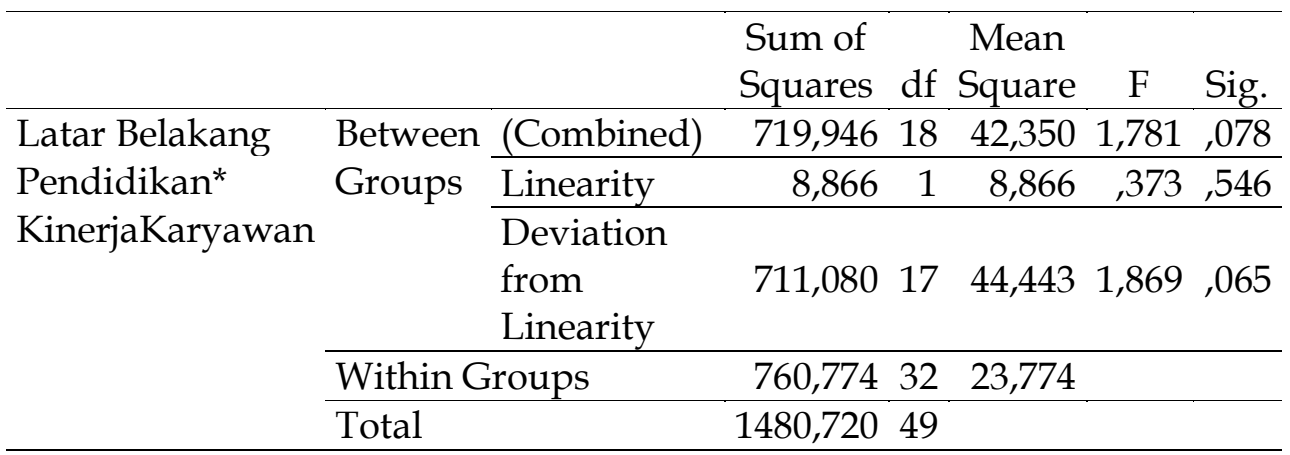

Berdasarkan output pada tabel 3 uji linieritas antara variabel bebas (Latar Belakang Pendidikan $\mathrm{X}_{2}$ ) dengan variabel terikat (Kinerja karyawan Y) dilihat dari Deviation From Linearity, menurut hasil perhitungan didapatkan nilai sig Deviation From Linearity sebesar 0,065 antara Latar Belakang Pendidikan dengan kinerja karyawan. Menurut kriterianya jika harga Deviation From Linearity lebih besar dari taraf signifikansi yang diambil (5\%) berarti berhubungan linier tetapi jika harga Deviation From Linearity lebih kecil dari taraf signifikansi yang diambil (5\%) berarti berhubungan tidak linier. Dalam penelitian ini terbukti bahwa Deviation From Linearity antara variabel bebas dengan variabel terikatnya adalah lebih besar terhadap taraf signifikansinya $0,05(0,065>0,05)$. Maka dapat 
PERANAN GAYA KEPEMIMPINAN DAN LATAR BELAKANG PENDIDIKAN

DALAM MENINGKATKAN KINERJA KARYAWAN PT. INFOMEDIA SOLUSI HUMANIKA

Heni Cahya Ramdani, Femi Handayani, \& Islamiyah

disimpulkan bahwa Latar Belakang Pendidikan $\left(\mathrm{X}_{2}\right)$ dengan kinerja karyawan $(\mathrm{Y})$ bersifat linier. Artinya hubungan atau korelasi tersebut dapat dinyatakan dengan garis lurus. Apabila mempunyai hubungan atau korelasi yang linier positif maka variabel satu meningkat dan variabel yang lain akan meningkat, tetapi apabila korelasi atau hubungan yang linier negatif variabel satu meningkat maka variabel yang lain akan menurun.

\section{Uji Multikolinieritas}

\section{Tabel 4. Uji Multikolinieritas}

Coefficients ${ }^{a}$

\begin{tabular}{|c|c|c|c|c|c|c|c|}
\hline \multirow[b]{4}{*}{ Model } & \multicolumn{3}{|r|}{ Standardize } & \\
\hline & \multicolumn{2}{|c|}{$\begin{array}{l}\text { Unstandardize } \\
\text { d Coefficients }\end{array}$} & $\begin{array}{c}\mathrm{d} \\
\text { Coefficients }\end{array}$ & \multirow[b]{3}{*}{$\mathrm{T}$} & \multirow{3}{*}{ Sig } & \multicolumn{2}{|c|}{$\begin{array}{l}\text { Collinearity } \\
\text { Statistics }\end{array}$} \\
\hline & & Std. & & & & Toleranc & \\
\hline & B & Error & Beta & & & $\mathrm{e}$ & VIF \\
\hline 1 (Constant) & $\begin{array}{r}10,17 \\
4\end{array}$ & 4,338 & & 2,345 & $\begin{array}{r}, 02 \\
3\end{array}$ & & \\
\hline $\begin{array}{l}\text { Gaya } \\
\text { kepemimpina } \\
\mathrm{n}\end{array}$ & ,937 & ,077 & 872 & $\begin{array}{r}12,19 \\
2\end{array}$ & $\begin{array}{r}, 00 \\
0\end{array}$ & ,994 & $\begin{array}{r}1,00 \\
6\end{array}$ \\
\hline $\begin{array}{l}\text { Latar } \\
\text { Belakang } \\
\text { Pendidikan }\end{array}$ &,- 129 & ,063 &,- 146 & 2,041 & $\begin{array}{r}, 04 \\
7\end{array}$ & ,994 & $\begin{array}{r}1,00 \\
6\end{array}$ \\
\hline
\end{tabular}

a. Dependent Variable: Kinerja Karyawan

Berdasarkan hasil output diatas pada tabel 4 diketahui bahwa nilai Tolerance variabel Gaya Kepemimpinan $\left(\mathrm{X}_{1}\right)$ dan Latar Belakang Pendidikan $\left(X_{2}\right)$ sebesar 0,994 lebih besar dari 0,10. Sedangkan nilai VIF sebesar 1,006 kurang dari 10.Maka dapat disimpulkan bahwa tidak terjadi multikolinieritas antar variabel bebas. 


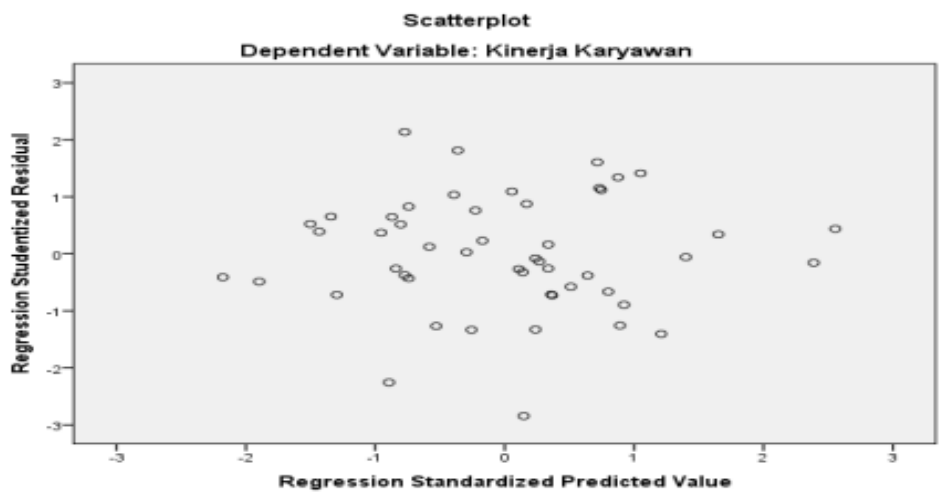

Gambar 1. Uji Heteroskedastisitas

Dari output pada gambar 4 dapat diketahui bahwa titik-titik tidak membentuk pola yang jelas, dan titik-titik menyebar diatas dan dibawah angka 0 pada sumbu Y. jadi dapat disimpulkan bahwa tidak terjadi masalah heterokedastisitas pada model regresi.

\section{Analisis Regresi Linier Berganda}

Tabel 5

Hasil Uji Analisis Regresi Liniear Berganda Unstandardized Standardized Coefficients Coefficients

Std.

\begin{tabular}{|c|c|c|c|c|c|}
\hline Model & $\mathrm{B}$ & Error & Beta & $\mathrm{t}$ & Sig. \\
\hline $1 \overline{(\text { Constant })}$ & 10,174 & 4,338 & & 2,345 & ,023 \\
\hline $\begin{array}{l}\text { Gaya } \\
\text { Kepemimpin } \\
\text { an }\end{array}$ & ,937 & ,077 & 872 & $\begin{array}{r}12,19 \\
2\end{array}$ & ,000 \\
\hline $\begin{array}{l}\text { Latar } \\
\text { Belakang } \\
\text { Pendidikan }\end{array}$ &,- 129 & ,063 &,- 146 & $-2,041$ & ,047 \\
\hline
\end{tabular}

a. Dependent Variable: Kinerja Karyawan

Setelah penulis melakukan pengujian model berupa asumsi klasik yakni Multikolinearitas dan Heteroskedastisitas yang terbukti tidak terdapat pelanggaran asumsi klasik, sehingga penulis dapat melanjutkan 
PERANAN GAYA KEPEMIMPINAN DAN LATAR BELAKANG PENDIDIKAN

DALAM MENINGKATKAN KINERJA KARYAWAN PT. INFOMEDIA SOLUSI HUMANIKA

Heni Cahya Ramdani, Femi Handayani, \& Islamiyah

anasis data dengan menggunakan model regresi berganda adapun hasil estimasi regresi adalah sebagai berikut:

$$
\begin{gathered}
\mathrm{Y}=\mathrm{a}+\mathrm{b} 1 \mathrm{x} 1+\mathrm{b} 2 \times 2+\mathrm{e} \\
\mathrm{Y}=10,174+0,937 \times 1-0,129 \times 2+e
\end{gathered}
$$

Keterangan:

$\mathrm{Y}=$ Kinerja Karyawan

$\mathrm{a}=$ Konstanta

$\mathrm{x} 1=$ Gaya Kepemimpinan

x2 = Latar Balakang Pendidikan

Dari persamaan di atas, dapat dijelaskan sebagai berikut:

a. Konstanta sebesar 10,174 menunjukkan nilai kinerja karyawan sebelum dipengaruhi oleh variabel gaya kepemimpinan, latar belakang pendidikan adalah positif.

b. Koefisien $\mathrm{b} 1=0,937$ menunjukkan setiap peningkatan 1 skor gaya kepemimpinan akan meningkatkan kinerja karyawan sebesar 0,937 dengan asumsi variabel-variabel bebas lainnya konstan. Nilai keofesien regresi pada variabel gaya kepemimpinan bertanda positif, artinya bahwa jika gaya kepemimpinan semakin baik, maka akan meningkatkan kinerja karyawan.

c. Koefisien b2 $=-0,129$ menunjukkan setiap peningkatan 1 skor latar belakang pendidikan akan menurunkan kinerja karyawan sebesar 0,129 dengan asumsi variabel-variabel bebas lainnya konstan. Nilai keofesien regresi pada variabel Latar Belakang Pendidikan bertanda negatif, artinya bahwa jika Latar Belakang Pendidikan meningkat maka akan menurunkan kinerja karyawan.

\section{Uji t}

Uji T digunakan untuk menguji apakah variabel independen berpengaruh secara parsial terhadap variabel dependen. Berdasarkan hasil statistik pada tabel 5 diatas dapat ditarik kesimpulan bahwa:

a. Gaya Kepemimpinan - Kinerja Karyawan. Hasil estimasi model regresi menghasilkan $t_{\text {hitung }}$ Gaya Kepemimpinan positif $(+12,192)>$ $t_{\text {tebel }}(2,012)$. Nilai probabilitas adalah sig $=0,000<$ alpha $(0,05)$ yang berarti secara parsial Gaya Kepemimpinan berpengaruh positif dan signifikan terhadap Kinerja Karyawan pada tingkat signifikansi 5 persen, dengan syarat ceteris paribus. Hasil tersebut menunjukkan bahwa hipotesis pertama yaitu Gaya Kepemimpinan positif dan signifikan terhadap Kinerja Karyawan terbukti. (Ho) ditolak dan (Ha) diterima. 
b. Latar Belakang Pendidikan - Kinerja Karyawan. Hasil etimasi model regresi menghasilkan thitung Latar Belakang Pendidikan Negatif ($2,041)<t_{\text {tebel }}(2,012)$. Nilai probabilitas adalah sig $=0.047>$ alpha $(0,05)$ yang berarti secara parsial Latar Belakang Pendidikan berpengaruh yang signifikan terhadap Kinerja Karyawan pada tingkat signifikansi 5 persen, dengan syarat ceteris paribus. Hasil tersebut menunjukkan bahwa hipotesis kedua yaitu Latar Belakang Pendidikam berpengaruh signifikan terhadap Kinerja Karyawan terbukti. (Ho) ditolak dan (Ha) di terima.

Uji F

\begin{tabular}{|c|c|c|c|c|c|}
\hline \multicolumn{6}{|c|}{$\begin{array}{c}\text { Tabel 6. Uji F } \\
\text { ANOVA }^{\mathbf{a}}\end{array}$} \\
\hline Model & Sum of Squares & Df & Mean Square & $\mathrm{F}$ & Sig. \\
\hline 1 Regression & 885,563 & 2 & 442,781 & 74,908 &, $000^{\mathrm{b}}$ \\
\hline Residual & 277,817 & 47 & 5,911 & & \\
\hline Total & 1163,380 & 49 & & & \\
\hline
\end{tabular}

a. Dependent Variable: Kinerja Karyawan

b. Predictors: (Constant), Latar Belakang Pendidikan, Gaya Kepemimpinan

F hitung $>$ F tabel $(74,908>3,195)$ dan signifikansi $<0,05(0,000<$ 0,05), maka $\mathrm{H}_{0}$ ditolak, jadi dapat disimpulkan bahwa Gaya Kepemimpinan dan Latar Belakang Pendidikan secara bersama-sama berpengaruh terhadap kinerja karyawan. Artinya bahwa terdapat pengaruh secara simultan antara semua variabel bebas terhadap variabel terikat.

\section{Koefisien determinasi $\left(\mathbf{R}^{2}\right)$}

Tabel 7. Korfisien Determinasi

\begin{tabular}{lrrrr}
\hline Model & R & R Square & Adjusted R Square Std. Error of the Estimate \\
\hline 1 &, $872^{a}$ &, 761 &, 751 & 2,43126 \\
\hline
\end{tabular}

a. Predictors: (Constant), Latar Belakang Pendidikan, Gaya Kepemimpinan

Berdasarkan tabel 4.15 menunjukkan koefisien regresi (R) sebesar 0,872 dengan koefisien determinasi (R2) sebesar 0,761. Nilai tersebut menunjukkan bahwa 76,1\% Kinerja Karyawan dipengaruhi oleh Gaya Kepemimpinan dan Latar Belakang Pendidikan. Sedangkan sisanya 
PERANAN GAYA KEPEMIMPINAN DAN LATAR BELAKANG PENDIDIKAN

DALAM MENINGKATKAN KINERJA KARYAWAN PT. INFOMEDIA SOLUSI HUMANIKA

Heni Cahya Ramdani, Femi Handayani, \& Islamiyah

sebesar $23,9 \%$ dipengaruhi oleh variabel lain yang tidak diteliti dalam penelitian ini, seperti pelatihan, motivasi dan pengembangan.

\section{E. KESIMPULAN}

Kesimpulan yang dapat diambil berdasarkan hasil olahan data pada penelitian ini tentang Peranan Gaya Kepemimpinan dan Latar Belakang Pendidikan terhadap Kinerja Karyawan pada PT Infomedia Solusi Humanika, diantaranya:

1. Gaya kepemimpinan berpengaruh positif dan signifikan terhadap kinerja karyawan. Berdasarkan hasil analisis data ini dapat disimpulkan bahwa hipotesis pertama yang menyatakan ada pengaruh positif secara parsial dan signifikan terbukti kebenarannya. Semakin tinggi skor gaya kepemimpinan semakin tinggi kinerja karyawan.

2. Latar belakang pendidikan berpengaruh negatif dan signifikan terhadap kinerja karyawan. Berdasarkan hasil analisis data ini dapat disimpulkan bahwa hipotesis pertama yang menyatakan ada pengaruh positif secara parsial dan signifikan tidak terbukti kebenarannya. Semakin tinggi skor latar belakang pendidikan semakin rendah kinerja karyawan.

3. Gaya kepemimpinan dan latar belakang pendidikan berpengaruh positif dan signifikan terhadap kinerja karyawan.

\section{REFERENSI}

Kapahang, J. O., Kojo, C., and Uhing, Y. (2014). Pendidikan, Pengalaman dan Kompetensi Pengaruhnya terhadap Kinerja Karyawan Pada Pt. Pln (Persero) Wilayah Suluttenggo. J. EMBA, vol. 2, no. 4, pp. 503-513.

Guterres, L. A., and Supartha, W. G. (2016). Pengaruh Gaya Kepemimpinandan Motivasi Kerja terhadap Kinerja Guru, vol. 5, p. 26.

Saputra, A. and Natassia, A. (2014). Pengaruh Gaya Kepemimpinan Dan Motivasi Kerja Terhadap Kinerja Karyawan Badan Pusat Statistik (Bps) Kota Padang," J. Ekon. dan Pendidik. Ekon., vol. 2, no. 2, pp. 134-143.

Pentana, S., and Ardiani, W. (2016). Dampak latar belakang pendidikan, pelatihan dan penempatan pegawai terhadap kinerja pegawai. JURIKOM, vol. 3, pp. 435-442. 2016.

Setiawan, I. K. Y. (2015). Pengaruh Latar Belakang Pendidikan dan 
Pengalaman Kerja Terhadap Kinerja Karyawan Pada PT. Federal International Finance (FIF) Group Cabang Singaraja," J. Jur. Pendidik. Ekonomi, vol. 5, no. 1, pp. 1-11.

Malayu, H. S. P. (2007). Manajemen Sumber Daya Manusia. Jakarta : Bumi Aksara.

Mathis, R. L. \& Jaction, J. H. (2002). Manajemen Sumber Daya Manusia. Jakarta: Salemba Empat.

Mujiatun, S. (2011). Pengaruh Gaya Kepemimpinan terhadap Kinerja Karyawan di Yayasan Pendidikan Sinar Husni. J. Manaj. Bisnis, vol. 11, no. 1, pp. 1693-7619.

Sugiono. (2015). Metode Penelitian Pendidikan. Bandung: Alfabeta. 